\title{
Dental age estimation - Literature review
}

\author{
Odzhakov F and Apostolov A* \\ Department of Forensic Medicine and Deontology, Medical Faculty, Medical University - Sofia, 1431, Bulgaria
}

\begin{abstract}
The forensic investigation of unidentified bodies is common in expert practice. Given the various changes that occur with biological human characteristics after death, it is not uncommon for this task to challenge the forensic doctor. The requirement for a forensic practitioner is to provide the most accurate guidelines for the investigation to identify the person.

Determining the individual calender age at the time of death involves the use of a variety of biochemical, morphological and histological techniques. Dental age estimation is one of the possible approaches towards that task and the scientific literature provides a wealth of sources of information on a variety of methods, their technical implementation, and the underlying mechanisms.

Only when the circle of suspected identities is narrowed, it is possible to proceed to identity verification by DNA-analysis. This is the reason why various techniques and methods for dental age estimation have been researched through the years and the following review aims in presenting a concise summary of some of the more significant ones.
\end{abstract}

\section{Introduction}

The forensic investigation of unidentified bodies is common in expert practice. Given the various changes that occur with biological human characteristics after death, it is not uncommon for this task to challenge the forensic doctor. The requirement for a forensic practitioner is to provide the most accurate guidelines for the investigation to identify the person.

In a number of cases of found unidentified deceased, facial recognition is impossible, given the stage of decomposition or the circumstances in which the body has been retrieved (fire, water, etc.). In such cases, it is necessary to apply scientific methods in order to obtain the most precise and accurate information.

In the forensic practice, the most widely proven scientific method for identification is DNA analysis. A sample of the deceased taken during their forensic examination is tested promptly with samples of suspected relatives of the deceased to establish a kinship relationship. In order to maximize the effectiveness of the analysis and to minimize the financial burden, it is necessary to narrow down the circle of suppositions for which a test is to be carried out. It is precisely the range of scientific methods used to narrow the circle of alleged identities of the unknown deceased, that are a challenge to the forensic scientist. At present, the methods used aim at determining anthropometric and biological characteristics. It is imperative that sex, height, race and calendar age are determined in each case. The latter are determined by purposeful research, comparison and interpretation of the results at the macroscopic level. Only then, when the circle of suspected identities is narrowed, it is possible to proceed to identity verification by DNAanalysis.

\section{Historical background}

Determining the individual calender age at the time of death involves the use of a variety of biochemical, morphological and histological techniques. According to the "Recommendations for
Age and Sex Diagnostics of Skeletons" [1], the determination of the individual calendar age includes the stages of dental development, the epiphysic saturation status, the status of ossification centers, the obliteration of the cranial suturi, the condition of the pubic symphysis surface and the anatomical features of the femur head [2]. Rösing et al. also explore and attach importance to mineralization and tooth growth in adolescents by producing some useful standards in determining the calendar age of skeletons. Other authors attribute importance to some more advanced techniques such as, for example, racemization of aspartic acid, number of layers of dental cement, and evaluation of histological features of the bones [3].

The use of dental status in forensic practice dates back more than 180 years ago when the growth of teeth was used in relation to child labor.

Saunders's suggestion raises the question of the relevance of gingival mumps and dental development in determining the calendar age. The problem of decimating the environmental factors, as well as the hereditary ones, gives rise to discussions. There is a consistently poor relationship between dental formation and factors such as social status, diet and growth and body development [4]. Demirjian's research concludes that dental development has no significant relationship to maturity indicators, menarche, height growth or skeletal maturity [5]. These results predict that the mechanisms that regulate dental growth and development are independent on common growth mechanisms and are closely related to the age of the patient. In addition, tooth

${ }^{\star}$ Correspondence to: Apostolov A, Department of Forensic Medicine and Deontology, Medical Faculty, Medical University - Sofia, 1431, Bulgaria, E-mail: alexa2000@mail.bg

Key words: dental age, identification, forensic medicine

Received: December 17, 2018; Accepted: January 17, 2019; Published: January 21,2019 
formation is affected much less by malnutrition, endocrinopathies, and other pathological conditions than any other tissue in the human body. This circumstance was discussed in the study of adolescents with severe abnormalities affecting sexual maturation and bone age but demonstrating a weak to a missing effect on dental development [6].

On the other hand, it is known that bone age is influenced by nutrition factors [7]. The bone age of abnormally developed individuals, determined primarily by bone marrow examination and bone size, is a valuable marker for changes and growth defects when comparing dental and chronological age. In general, the condition of the skeleton helps determine the individual physiological age. Dental age, which is determined by hard dental tissue, is more closely related to the individual calender age [8].

Time periods of dental development are inherited, but also population-specific. Clearly staggered stages differ in their manifestations for different nationalities [9]. Compared to the formation (which involves the formation of an organic matrix and subsequent calcification), teeth eruption seems less resistant to external factors. It is known that dental growth can be affected by tooth decay, caries and malnutrition [10].

Another characteristic, besides the stable formation mechanisms, which determines the significant role of teeth in determining age at the time of death is the extreme strength and endurance of the dental rigid tissue. Often, in cases of decomposition, the only structures fit for examination are the teeth. This is due to the much lower degree of their environmental damage - animals, humidity, microbial activity, mechanical forces and high temperatures. It has been successfully demonstrated that even cremated teeth provide sufficient material for a fairly accurate determination of the calendar age [11]. In addition, there are a number of methods applicable even in the case of preserving a single tooth. This provides the opportunity to determine the individual calendar age with minimum deviations [12].

\section{Principles of determination of dental age}

The scientific literature provides a wealth of sources of information on a variety of methods, their technical implementation, and the underlying mechanisms. Dental age can be determined by growth features such as mineralization, gingival clinging, quantum cementation, or narrowing of the pulp space. Degenerative changes such as tooth attrition or periodontal involution are also related to calendar age. In addition, a variety of other parameters - fluorescence intensity, dentin density, racemization of aspartic acid or dentinal sclerosis - help assess the age-related changes in dental tissue and can be used to determine human calender age. The basic principles of age-setting, as well as some age-dependent changes in human teeth, will be discussed.

\section{Degree of tooth formation}

Dental formation is a complex process that begins with structural reorganization and a change in the embryonic cell phenotype. Deciduous teeth begin their development during the 6th to 8th weeks of gestation; permanent teeth - about the 20th week of gestation [13]. When determining the dental age, the term "tooth formation" generally refers to the mineralization of the dental rigid tissue rather than the non-mineralization stages of tooth growth. The reason behind this is probably the possibility of the mineralized tissue being examined radiologically, as well as its resistance to decomposition [14].

Literature data on dental time periods are based on radiological, histological and morphological studies. In the 1970s. Calonius develops and publishes histological criteria that allow the determination of the calendar age from 7 weeks of gestation to 3 years of age. These criteria include bone, salivary and dental formation characteristics [15].

Data published by Schour and Massler in 1941. represent 22 stages of dental development from 5 months of intrauterine life up to 35 years [16]. The Schour and Massler tables have become a classic example of the commonly used atlas approach.

In 1988, Kahl and Schwarze process the data of Schour and Massler and show a slowdown in the development of the permanent dentition among the selected cohort group used in their studies [17].

Another scientific study led to the reworking of the Schour and Massler diagrams was conducted by Ubelaker in 1978, which developed diagrams based on his Indian studies. These diagrams are included in the "Recommendations for Age and Sex Diagnoses of Skeletons" in 1980 [18].

In 1955, Gleiser and Hunt detail the stages of calcification of the first mandibular molar after performing radiographic and follow-up studies in this area [19].

Another example of an atlas approach is that of Gustafson and Koch, which is based on the mineralization initiation, the completed crown development, the eruption of the tooth and the completion of root development.

In his study Demirjian distinguishes between 4 stages of crown development and 4 of the roots, which are based on their species in radiological research. This method uses a point system to form 7 (or 4) mandibular tooth. Each stage corresponds to a specific tooth result. The collection of all results reflects the Dental Maturity Score. The authors also develop a percentage distribution that determines the individual calendar age [20].

The third molars are the most varied teeth of their anatomical features, the agenesis and the age of eruption. Determining the age for forensic practice using third-molar development studies is used in the age range 14-21 when all other teeth have completed their formation. According to the recommendations of the Study Group on Forensic Age Diagnostics, the Demirjian method has the greatest predictive and practical value [21]. His method has the advantage that the stages of development are clearly defined, according to radiographs, diagrams and written criteria.

In 2004, Ozle published a detailed study of the ethnic differences in third molar mineralization, based on an analysis of over 3,000 conventional orthopanthomograms. It has been demonstrated that Japanese, German and South African individuals differ by up to 7 years, compared to Demirjian's decimated stages. For this reason, the authors believe that it is imperative to use population-specific research to determine the individual calendar age for optimal reproducibility and credibility [22].

\section{Speed of formation of dental crown structures}

The time intervals that take the formation of some characteristic of dental crown structures may be applied when determining the calendar age. The most commonly used examination technique is microscopic histological evaluation. In one of his scientific publications, Boyde is of the opinion that age can be determined by the number of prisms of the transverse stretch [23]. An alternative tooth feature that can be found on the crown is the lines of Recius (brown striations of Recius) that are established between the enamel- 
dentinal junction in the occlusal direction. The neonatal line, which represents the borderline between pre- and postnatally formed enamel (and dentin), is often used to determine the calendar age at the time of death. This characteristic is the first distinct brown line of Recius and is found in deciduous teeth as well as in the permanent first molar. It is assumed that its appearance is the result of a metabolic disorder occurring during pregnancy [24]. This feature, along with the total number of transitions, allows the determination of the calendar age at the time of death. The perikimate, a small visible line on the surface of the enamel, is the surface appearance of the Recius lines along the tooth circumference. A study was conducted using only the characteristics of the perikimate [25], where the authors applied the intervals for their formation in modern humans to determine the calendar age of the hominids.

\subsection{Changes of the pulp-dentinal complex associated with age}

Dentin, unlike the enamel, continuously forms additional tissue. Secondary dentin is formed physiologically and is a slow process, expressed in cell growth in pulpal space. The formation of secondary dentin begins after dentinogenesis [26]. There is little difference between primary and secondary dentin, which can be detected by coloring, microengraphy or polarization microscopy [27]. Prolonged formation of secondary dentin is considered to be the result of masticatory stress as well as temperature amplitudes [28]. Bodecker first found that the accumulation of secondary dentine was associated with calendar age [29]. The accumulation of secondary dentine leads to a significant reduction in pulp space and may contribute to the obliteration of the root canal. In this regard, Gustafson introduces the linear measurement of secondary dentine as one of his 6 criteria for the determination of the calendar age.

Some authors direct their studies to determine the pulp / tooth ratio in orthopanthomograms and periapical X-rays [30]. Another research approach involves the combined analysis of labiolingual and mesial periapical X-rays of lower and upper canine teeth of skeletal corpses [31].

Dentin sclerosis (root transparency) is another indicator of the pulpodentine complex that was first described by Tomes in 1861 . This characteristic undergoes significant changes in the course of aging, but is also a form of protective response to caries, wiping and medication treatment [32].

Transparency of root dentin was first used in the 1950s. by Gustafson, as one of the 6 criteria proposed by him [33].

Using other research approaches, some authors attempt to assess the degree of translucency of root dentin by computerized densitometric analysis. The technique aims at avoiding the most common problem with the distinction between opaque and transparent dentin, both in histological sections and in whole teeth. The results do not justify the conclusion that computer analysis has an advantage [34].

The Lamendin method is another technique that is based on the application of dentinal transparency for the purposes of determining the individual's calendar age. Lamendin presents a single tooth age approach using the degree of paradontosis and root transparency [35]. The method demonstrates satisfactory results, as well as a correlation between gender and the result obtained. Although the Lamendin method demonstrates some degree of subjectivity due to the inaccurately differentiated boundary between transparent and opaque dentine, it provides a practical possibility of setting a calendar age [36].

\section{Quantitative assessment of tooth cement changes with age}

Cement is a rigid tooth tissue with a mineralized organic matrix that forms points for connecting the periodontal fibers that attach the tooth to the alveolar bone. The cement of human tooth roots does not undergo prolonged physiological remodeling, like bones. The linear structure is conditioned by structural differences in the mineral phase - an optical phenomenon most likely due to a changed orientation of the mineral crystals - and reflects the cyclical annual accumulation [37]. A pair of bright and dark lines should reflect one calendar year of individual life. If the number of cement rings is added to the peculiarities of the erupting tooth, it is possible to determine the individual calendar age.

Gustafson introduced the use of tooth cement as a characteristic for the determination of the calendar age [33], and Zander and Hurzeler first described a relationship between cement growth and calendar age [38].

Grading of cement layers is currently assessed as a "second line", after racemization of aspartic acid, when determining the age [39]. Due to the fact that the nature of the mechanism by which the cement layers are formed is not fully understood, there is a need to carry out further research in this regard.

\section{Age-related tooth color changes}

It is common knowledge that the teeth change color with the years, showing yellowish and brownish shades. Progressive staining is due to the degradation of organic constituents of dental rigid tissue, the accumulation of external substances in enamel and dentin, mineralization and related changes in the refractive index [40]. The problem of objective assessment of the color of the teeth has not yet been resolved. In addition, the question of the discoloration of the root of the teeth and their resistance to external influences is unclear.

\section{Changes in chemical composition of teeth with age}

A chemical element which content increases with age is nitrogen. The widespread conception explains this change with the accumulation of a pigment that changes the color of the older teeth [41].

Another change in the chemical composition of dental tissue that is useful in determining the age of the patient is the racemization of aspartic acid. In the living organism, the proteins are mainly composed of the L-isomer of the amino acids that polarize the light to the left. Only certain molecules are physiologically synthesized with the D-isomer of the amino acids that polarize light to the right. Changing the L- to $\mathrm{D}$-isomer (racemization) of amino acids occurs both in life and after death. Racemization is influenced by environmental factors such as $\mathrm{pH}$, humidity, etc. this process can be detected with metabolically inactive or bradythrophic tissues such as teeth. The racemisation of aspartic acid is also used in the study of tissue changes as a secondary phenomenon [42].

\section{Density of teeth and its relation to the calendar age}

A number of scientific studies address the issue of changing the density of human teeth and its attitude towards the calendar age. Shikano finds that the incidence of incisors increases with age [43].

In his study, Heuschkel estimates the density of 130 teeth by a pycnometer. Remaining moisture was not removed, but the pulp cavity was pierced, and the tooth was sifted into components (crown, root, and middle part). The analysis does not focus on the individual components of the teeth. A standard deviation between 0.123 and 0.131 was found, with no significant evidence of age relative to the age [44]. 
Rheinwald examines the relative density of the enamel by the pycnometer method. The crowns were manually removed from the roots by carving, and the results clearly showed an increase in density with age. This trend, observed in both dentine and enamel, is a direct consequence of age-related changes in mineral composition and tooth structure [45].

3.8. Epidemiological criteria for assessing the morphological characteristics of human teeth.

An example of an epidemiological criterion for determining the age is the DMFT index. The index quantifies the severity of the carious changes and their effects in the population. It is a function of the carious (D), missing $(\mathrm{M})$ and obtuse $(\mathrm{F})$ permanent teeth $(\mathrm{T})$ in the individual (National Dental Epidemiology Program for England, 2016). Friedrich examined orthopanthomograms of patients aged 1424 years in order to derive a result on the applicability of obtunded wisdom teeth in the determination of the calendar age. The values for "carious", "obtuse", "carious and obtuse" and "no changes" are detailed and statistically processed. Most wisdom teeth in the cohort group do not show either carious changes or obturations. However, the authors establish a correlation between obtrusive wisdom teeth and a calendar age over 18 years [46].

The DMFT epidemiological index can be used for guidance but is not particularly relevant in determining the age of the individual due to individual differences, diet and effectiveness of caries prophylaxis for the respective population.

\section{Attrition as a criterion when setting a calendar age}

Attrition is the most prominent evidence of the effect of calendar age on the human dentition - the loss of dental material on incisal edges and occlusal surfaces. Attrition is not only a consequence of the prolonged action of masticatory forces, it is also associated with dental hygiene, dysangia, bruxism and eating habits. In modern people, deletion is a slow process, so its applicability as the sole criterion for determining age is limited. For this reason it is only possible to use it in the context of anthropological material research. The morphology of erasure is assessed by examining the incisal and occlusal tooth surface by applying a corresponding method to determine the specific calender age. Most methods used to quantify attrition are based on relative subjectivity, so the results show a significantly broad range of age. It is advisable, if possible, to avoid the use of dental attrition as the sole criterion for determining age. The optimal use of dental attrition involves evaluating other factors in order to achieve the most reliable results [47].

\section{Combined methods}

In order to determine the calendar age in cross sections, Gustafson combines six age-dependent variables (attrition, periodontal binding, secondary dentine, cement accumulation, root resorption and root dentinal transparency) [33]. The mor[phological appearance of each of the variables allows its identification with a coefficient of 0 to 3 . The aggregate result determines the age with the Gustafson linear regression equation, which should be applicable to each type of tooth.

Another scientific approach was introduced by Johanson in 1971, which implements a new system for attributing coefficients to Gustafson's original technique. In addition, he developed a number of linear regression equations and found that the root dentin translucency was most dependent on the calendar age, followed by the secondary dentin.

\section{Conclusion}

Research within the mechanisms of dental change and the onset of various age-dependant alternations would be of great importance to the initial distinguishing forensic medical expertise. The application of such methods for the purpose of identification of unknown deceased would be of upmost aid to the forensic specialist and would lead to narrowing the number of supposed missing persons.

Given the current state of fund raising and budget distribution among the sectors of health care, the development of accurate models and methods for age estimation at a minimum cost is crucial. The discussed methods given their practical approach are a solid foundation for the onset of determining age during forensic medical examination of deceased with unknown identity.

\section{References}

1. Miller CS, Dove SB, Cottone JA (1988) Failure of use of cemental annulations in teeth to determine the age of humans. J Forensic Sci 33: 137-143. [Crossref]

2. Ohtani S, Sugimoto H, Sugeno H, Yamamoto S, Yamamoto K (1995) Racemization of aspartic acid in human cementum with age. Arch Oral Biol 40: 91-95. [Crossref]

3. Olze A, Bilang D, Schmidt S, Wernecke KD, Geserick G, et al. (2005) Validation of common classification systems for assessing the mineralization of third molars. Int $J$ Legal Med 119: 22-26. [Crossref]

4. Prince DA, Ubelaker DH (2002) Application of Lamendin's adult dental aging technique to a diverse skeletal sample. J Forensic Sci 47: 107-116. [Crossref]

5. Rosing FW, Graw M, Marré B, Ritz-Timme S, Rothschild MA, et al. (2007) Recommendations for the forensic diagnosis of sex and age from skeletons. Homo 58 75-89. [Crossref]

6. Rosing FW, Kvaal SI (1998) Dental Age in Adults - A Review of Estimation Methods In: Alt KW, Rosing FW, Teschler-Nicola M (eds.) Dental Anthropology. Fundamentals, Limits, and Prospects. Wien, New York: Springer: 443-468.

7. Saunders E (1837) The Teeth a Test of Age, Considered with Reference to the Factory Children, Addressed to the Members of Both Houses of Parliament. London: Renshaw.

8. Schmeling A, Olze A, Reisinger W, Geserick G (2004) Forensic age diagnostics of living people undergoing criminal proceedings. Forensic Sci Int 144: 243-245.

9. Schmeling A, Dettmeyer R, Rudolf E, Vieth V, Geserick, G (2016). Forensic Age Estimation: Methods, Certainty, and the Law. Deutsches arzteblatt international 113: 44.

10. Demirjian A, Buschang PH, Tanguay R, Patterson DK (1985) Interrelationships among measures of somatic, skeletal, dental, and sexual maturity. Am J Orthod 88: 433-438.

11. Friedrich RE, Maydell LA, Ulbricht C, Scheuer HA (2005) Decayed, filled and missing teeth as a forensic-odontologic aid for determining the age above 18 years: A radiographic study of orthopantomograms from a group of teenagers and young adults. Arch Kriminol 216: 129-149.

12. Gleiser I, Hunt E (1955) Jr.The permanent mandibular first molar: its calcification, eruption and decay. Am J Phys Anthropol 13: 253-283.

13. Gustafson g (1950) Age determination on teeth. J Am Dent Assoc 41: 45-54. [Crossref]

14. Haavikko K (1970) The formation and the alveolar and clinical eruption of the permanent teeth. An orthopantomographic study. Suom Hammaslaak Toim 66: 103170. [Crossref]

15. Anderson DL, Thompson GW, Popovich F (1976) Age of attainment of mineralization stages of the permanent dentition. J Forensic Sci 21: 191-200. [Crossref]

16. Schour I, Kronfeld R. ArchPathol (1938) Neonatal dental hypolasia analysis of the teeth of an infant with injury of the brain at birth. Tooth ring analysis: IV 26: 471-490.

17. SchourI., Massler M (1941) The development of the human dentition. Journal of the American Dental Association 28: 1153-1160.

18. Sheetal A, Hiremath VK, Patil AG, Sajjansetty S, Kumar SR (2013) Malnutrition and its oral outcome - a review. J Clin Diagn Res 7: 178-180. [Crossref]

19. Andreas O, Mahlow A, Schmidt S, Geserick G, Schmeling A (2004) [Radiologically determined DMF index variations for forensic age estimation of young adults. Arch Kriminol 214: 103-111. [Crossref] 
20. Balwant R, Jasdeep K (2013) Evidence-based forensic dentistry 978-3-642-28993-4 (Print) 978-3-642-28994-1 (Online).

21. Bang G (1989) Age changes in teeth: Developmental and regressive.In: Iscan, MY (ed.) Age markers in the human skeleton. Springfield: Charles C. Thomas: 211-235.

22. Bellastella A, Pisano G, Iorio S, Pasquali D, Orio F, et al. (1998) Endocrine secretions under abnormal light-dark cycles and in the blind. Horm Res 49: 153-157. [Crossref]

23. Benesova T, Ales H, Pilin A, Votruba J, Flieger M (2004) A modified HPLC method for the determination of aspartic acid racemization in collagen from human dentin and its comparison with GC. J Sep Sci 27: 330-334. [Crossref]

24. Black GV (1883) Tables of lines of contemporaneous calcification. Ann J Illinois State Dental Soc 1.

25. Bodecker CF (1925) A consideration of some of the changes in the teeth from young to old age. Dental Cosmos 67: 543-549.

26. Lamendin H, Baccino E, Humbert JF, Tavernier JC, Nossintchouk RM, et al. (1992) A simple technique for age estimation in adult corpses: the two criteria dental method. $J$ Forensic Sci 37: 1373-1379. [Crossref]

27. Lipsinic FE, Paunovich E, Houston GD, Robison SF (1986) Correlation of age and incremental lines in the cementum of human teeth. J Forensic Sci 31: 982-989. [Crossref]

28. Solheim T (1988) Dental color as an indicator of age. Gerodontics 4: 114-118. [Crossref]

29. Sunderland EP, Smith CJ, Sunderland R (1987) A histological study of the chronology of initial mineralization in the human deciduous dentition. Arch oral biol 32: 167-174

30. Ten Cate AR (2013) Oral histology: development, structure, and function. St. Louis: Mosby.

31. Wittwer-Backofen U, Gampe J, Vaupel JW (2004) Tooth cementum annulation for age estimation: results from a large known-age validation study. Am J Phys Anthropol 123 119-129. [Crossref]

32. BommannavarS, KulkarniM (2015) Comparative study of age estimation using dentinal translucency by digital and conventional methods. Journal of Forensic Dental Sciences 7: 71-75.

33. Boyde AE, Berkovitz BKB, Boyde A, Frank RM, Hohling HJ, Moxham BJ, et al. (1989) Teeth, Handbook of Microscopic Anatomy. New York, Berlin and Heidelberg: Springer Verlag: 309-473
34. Brudevold F (1957) Age changes in dental enamel. Norske Tannlaegeforen Tid 67: 451

35. Burns KR, Maples WR (1976) Estimation of age from individual adult teeth. J Forensic Sci 21: 343-356. [Crossref]

36. Calonius PE, Lunin M, Stout F (1970) Histologic criteria for age estimation of the developing human dentition. Oral Surg Oral Med Oral Pathol 29: 869-876. [Crossref]

37. Heuschkel HJ, Koch R, Sussmann H (1979) Determination of the total tooth density of permanent human teeth and their significance for the age of the tooth bearer. Tooth mouth and jawbone 67: 583-590.

38. Hillson S (1996) Dental anthropology. Camebridge: Camebridge university Press 1996.

39. Kuhns LR, Sherman MP, Poznanski AK (1972) Determination of neonatal maturation on the chest radiograph. Radiology 102: 597-603. [Crossref]

40. Kvaal S, Solheim T (1989) Fluorescence from dentin and cementum in human mandibular second premolars and its relation to age. Scand J Dent Res 97: 131-138. [Crossref]

41. Yamamoto t (2016) Histology of human cementum: Its structure, function, and development. Japanese Dental Science Review 52: 63-74

42. Cameriere R, Ferrante L, Belcastro MG, Bonfiglioli B, Rastelli E, et al. (2007) Age estimation by pulp/tooth ratio in canines by mesial and vestibular peri-apical X-rays. $J$ Forensic Sci 52: 1151-1155. [Crossref]

43. Cameriere R, Ferrante L, Belcastro MG, Bonfiglioli B, Rastelli E, et al. (2007) Age estimation by pulp/tooth ratio in canines by peri-apical X-rays. J Forensic Sci 52: 166 170. [Crossref]

44. Widbiller M, Eidt A, Lindner SR, Hiller KAH, Schweikl W (2017) Dentine matrix proteins: isolation and effects on human pulp cells. Inter endodontic j 51: e278-e290. [Crossref]

45. Miles AEW (1963) Dentition in the estimation of age. J Dent Res 42: 225-263.

46. Zapico SC (2017) Mechanisms linking aging, diseases and biological age estimation, CRC Press, 2017.

Copyright: (C2019 Odzhakov F. This is an open-access article distributed under the terms of the Creative Commons Attribution License, which permits unrestricted use, distribution, and reproduction in any medium, provided the original author and source are credited. 